\title{
Effect of pre-annealing treatment on the microstructure and mechanical properties of extruded $\mathrm{Al}-\mathrm{Zn}-\mathrm{Mg}-\mathrm{Cu}$ alloy bars
}

\author{
Zhi-hao Zhang ${ }^{1)}$, Jie Xue ${ }^{2)}$, Yan-bin Jiang ${ }^{1)}$, and Feng Jin ${ }^{1)}$ \\ 1) Institute for Advanced Materials and Technology, University of Science and Technology Beijing, Beijing 100083, China \\ 2) Beijing Hangxing Machine Manufacture Co., Ltd, Beijing 100083, China \\ (Received: 10 May 2017; revised: 3 July 2017; accepted: 7 July 2017)
}

\begin{abstract}
Taking extruded $\mathrm{Al}-\mathrm{Zn}-\mathrm{Mg}-\mathrm{Cu}$ alloy (7A04 alloy) bars as the research object, the effect and mechanism of pre-annealing treatments on the microstructure and mechanical properties of the aged alloy bars were investigated. The results show that a pre-annealing treatment at $350^{\circ} \mathrm{C}$ for $15 \mathrm{~h}$ before a T6 treatment substantially reduced the sensitivity of the microstructure and mechanical properties of the extruded 7A04 aluminum alloy specimens toward the extrusion temperature. The average grain sizes of the specimens extruded at 390 and $430^{\circ} \mathrm{C}$ after T6 treatment were 3.4 and $8.1 \mu \mathrm{m}$, respectively, and their elongations to failure were $7.0 \%$ and $9.2 \%$, respectively. However, after pre-annealing $+\mathrm{T} 6$ treatment, the differences in both the grain sizes and the elongations of the specimens became small, i.e., their average grain sizes were 3.2 and $3.8 \mu \mathrm{m}$ and their elongations were $12.0 \%$ and $13.3 \%$, respectively. For the specimens extruded at the same temperature, pre-annealing treatment obviously improved the plasticity of the alloy, which is attributed to an increase in soft texture or to grain refinement in the specimens as a result of the pre-annealing + T6 treatment.
\end{abstract}

Keywords: aluminum alloy; hot extrusion; pre-annealing treatment; microstructure; mechanical properties

\section{Introduction}

The applications of aluminum alloy products in the fields of rail transportation and aerospace have led to more stringent requirements with respect to mechanical properties. In addition to the factors such as the alloy material, shape and size precision, and the surface quality, the homogeneity and consistency of alloys' microstructure and properties are also keys to ensuring high performance of formed products.

Extrusion is an important forming method for wrought aluminum alloys. Because of the characteristics of extrusion technology, an uneven temperature distribution inevitably exists in the extruded products along the length direction and in the cross section. For example, the maximum temperature difference in the cross section of a large profile can reach $60^{\circ} \mathrm{C}$ [1], leading to inhomogeneities in both the microstructure and the mechanical properties of the products along the length direction and in the cross section [2-5]; these inhomogeneities seriously affect the service life of ex- truded products and reduce the overall service performance of equipment.

Isothermal extrusion, which can be achieved via closed-loop speed control [6] or billet gradient temperature heating (cooling) [7], can effectively overcome the problem of nonuniform temperature distribution along the length direction of the extruded product. For the nonuniform temperature distribution in the cross section, the current main solution is to adjust the heat flow during extrusion (e.g., plastic deformation heat, friction heat, and heat transfer between the billet and mold) [1].

Some studies [8-11] have indicated that, when a deformed aluminum alloy was annealed at low temperatures (i.e., pre-annealing treatment), the stored deformation energy was partly consumed and the driving force of recrystallization nucleation and growth was reduced during the subsequent solution treatment, which affected the grain size of the alloy. Therefore, controlling the microstructure and mechanical properties of an aluminum alloy profile via a 
pre-annealing treatment is theoretically feasible.

In this paper, taking 7A04 aluminum alloy bars extruded at different temperatures as the research object, we investigated the effects of pre-annealing on the microstructure and mechanical properties of the extruded bars after solid solution and aging treatments (i.e., T6). The proper pre-annealing conditions that result in microstructure and mechanical properties as similar as possible for bars extruded at different temperatures can be obtained to reduce the sensitivity of the microstructure and mechanical properties of the alloy to the extrusion temperature. Finally, this work provided a reference for improving homogeneities in both the microstructure and the mechanical properties of the extruded profiles.

\section{Experimental}

The chemical composition of the 7A04 aluminum alloy billets used in the present work is shown in Table 1. The billets with a size of $\phi 40 \mathrm{~mm} \times 60 \mathrm{~mm}$ were subjected to a homogenization treatment at $460^{\circ} \mathrm{C}$ for $24 \mathrm{~h}$ [12] in an SGM-M30/12 box-type resistance furnace and were then immediately quenched in water at room temperature. The grain size of the billets after the homogenization treatment was approximately $28.2 \mu \mathrm{m}$. The homogenized billets were then extruded into round bars with a diameter of $8.4 \mathrm{~mm}$; the extrusion ratio was 23 .

Table 1. Chemical composition of the 7A04 aluminum alloy

\begin{tabular}{cccccccc}
\hline $\mathrm{Zn}$ & $\mathrm{Mg}$ & $\mathrm{Cu}$ & $\mathrm{Cr}$ & $\mathrm{Fe}$ & $\mathrm{Si}$ & $\mathrm{Mn}$ & $\mathrm{Al}$ \\
\hline 5.15 & 2.30 & 1.70 & 0.21 & 0.30 & 0.09 & 0.23 & Bal. \\
\hline
\end{tabular}

To reduce the influence of the difference in microstructure between the front and end of the bars on the experimental results, the specimens were collected from the middle section of the bars (i.e., the stable extrusion stage). The specimens were divided into two groups. One group was subjected to the $\mathrm{T} 6$ process $\left(475^{\circ} \mathrm{C}\right.$ for $1 \mathrm{~h}+120^{\circ} \mathrm{C}$ for $24 \mathrm{~h})$ [12]. The other group was treated by being pre-annealed (the annealing temperature ranged from 100 to $410^{\circ} \mathrm{C}$, and the holding time ranged from 0.5 to $20 \mathrm{~h}$ ) and then subjected to the $\mathrm{T} 6$ process.

The optical micrographs of the aged specimens (the observation position was the center of the specimens) were observed using a Zeiss Axiovert 200 MAT optical microscope. The specimens for optical microscopy were polished and etched in Graff Sargent agent $\left(1 \mathrm{~mL} \mathrm{HF}+16 \mathrm{~mL} \mathrm{HNO}_{3}+\right.$ $3 \mathrm{~g} \mathrm{CrO}_{3}+83 \mathrm{~mL}$ water). The grain size of the specimens was obtained by the linear intercept method. The degree of recrystallization and the grain orientation were detected by the electron backscattering diffraction (EBSD) technique. EBSD specimens were prepared by electrolytic polishing at a voltage of $25 \mathrm{~V}$ in $5 \mathrm{wt} \%$ perchloric acid at $-25^{\circ} \mathrm{C}$. The size and distribution of precipitates were observed by transmission electron microscopy (TEM).

The $\{111\},\{200\},\{220\}$, and $\{113\}$ incomplete pole figures for each specimen were constructed from the results obtained using a Brucker D8 Discovery texture tester. The orientation distribution function (ODF) of the expansion coefficient $l=22$ was obtained using the method of spherical harmonic series expansion; the "true ODF" $(l=23)$ was obtained by texture analysis to eliminate the influence of a ghost peak [13-14].

The tensile specimens with a diameter of $3 \mathrm{~mm}$ and a gauge length of $15 \mathrm{~mm}$ were machined with their axes parallel to the extrusion direction, consistent with the method specified in standard GB/T228.1-2010. Tensile tests were carried out at room temperature on an MTS-810 testing machine at a strain rate of $1 \times 10^{-3} \mathrm{~s}^{-1}$; tensile deformation was measured using an extensometer. Three samples corresponding to each condition were tested, and the average values are reported as the test results.

\section{Results}

Fig. 1 shows the average grain sizes of the specimens extruded at different extrusion temperatures after the T6 treatment. It reveals that the average grain size of the specimens in the cross section first increases and then decreases with increasing extrusion temperature; i.e., the sensitivity of the aged microstructure to the extrusion temperature differs. In addition, when the temperature of the extruded 7A04 aluminum alloy along the extrusion direction changes from 390 to $500^{\circ} \mathrm{C}$, the microstructure of the extruded product after T6 treatment is inhomogeneous. In particular, when the extrusion temperature is 390 and $430^{\circ} \mathrm{C}$, the difference in the average grain size of the two specimens (3.4 and $8.1 \mu \mathrm{m}$, respectively) is largest. Therefore, the specimens extruded at 390 and $430^{\circ} \mathrm{C}$ were used as the main research objects in the following experiments in this work.

The extruded specimens were pre-annealed at $100-410^{\circ} \mathrm{C}$ for $15 \mathrm{~h}$ and then subjected to T6 treatment; the average grain size of the T6-treated specimens is shown in Fig. 2, which reveals that the average grain size of the specimen extruded at $390^{\circ} \mathrm{C}$ changes little with the pre-annealing temperature, ranging from 3.2 to $3.4 \mu \mathrm{m}$. In the case of the specimen extruded at $430^{\circ} \mathrm{C}$, when the pre-annealing tem- 
perature was lower than $290^{\circ} \mathrm{C}$, the average grain size was approximately $8.0 \mu \mathrm{m}$. When the pre-annealing temperature was increased from 290 to $350^{\circ} \mathrm{C}$, the average grain size decreased sharply, reaching a minimum of $3.8 \mu \mathrm{m}$ at $350^{\circ} \mathrm{C}$. When the pre-annealing temperature was increased further, the average grain size increased. When the pre-annealing temperature exceeded $410^{\circ} \mathrm{C}$, the average grain size was approximately the same as the initial grain size. Therefore, the suitable pre-annealing temperature is $350^{\circ} \mathrm{C}$, which induces the least difference in the average grain size of the aged specimens extruded at 390 and $430^{\circ} \mathrm{C}$.

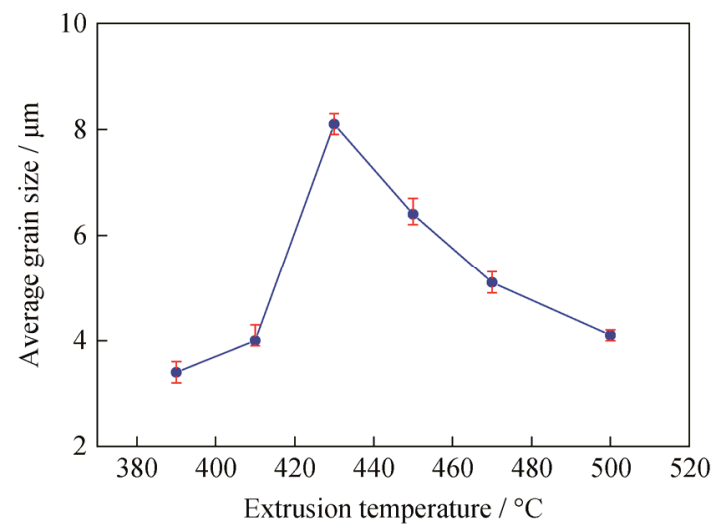

Fig. 1. Influence of extrusion temperature on the average grain size of the specimens after $\mathrm{T} 6$ treatment.

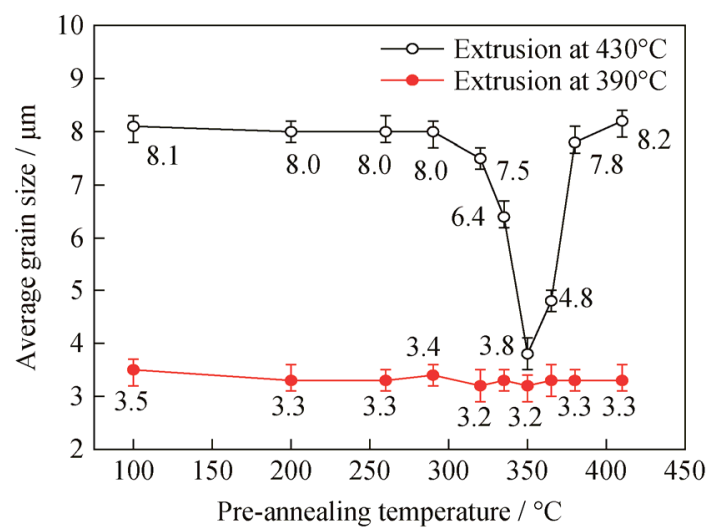

Fig. 2. Influence of pre-annealing temperature on the average grain size of the aged specimens (the pre-annealing time is $15 \mathrm{~h}$ ).

The average grain size of the extruded specimens treated by pre-annealing for different times and then by T6 treatment is shown in Fig. 3. The average grain size of the specimen extruded at $390^{\circ} \mathrm{C}$ is independent of the pre-annealing time. For the specimen extruded at $430^{\circ} \mathrm{C}$, when the pre-annealing time is approximately $0.5-10 \mathrm{~h}$, the average grain size also remains unchanged. However, when the pre-annealing time is greater than $10 \mathrm{~h}$, the average grain size decreases gradually and is approximately $3.8 \mu \mathrm{m}$ in the case of a pre-annealing time of $15 \mathrm{~h}$. With a further increase in pre-annealing time, the grain size increases conversely. Therefore, when the pre-annealing time is $15 \mathrm{~h}$, the difference in the average grain size of the specimens extruded at 390 and $430^{\circ} \mathrm{C}$ is least, and the average grain sizes are 3.3 and $3.8 \mu \mathrm{m}$, respectively, indicating that the suitable pre-annealing time is $15 \mathrm{~h}$.

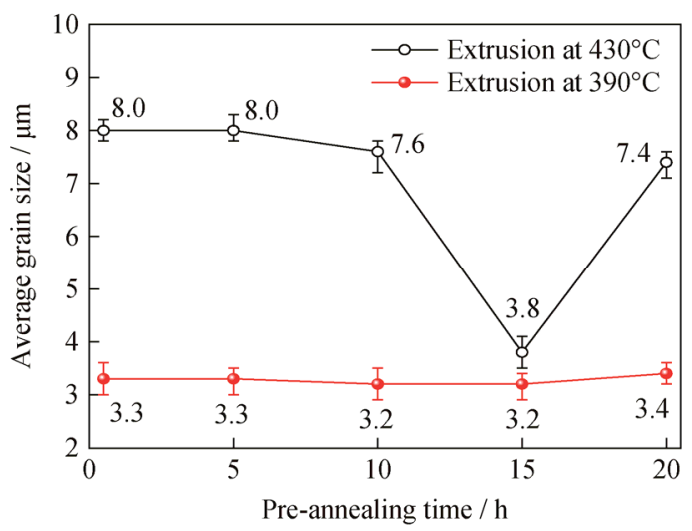

Fig. 3. Influence of pre-annealing time on the average grain size of aged specimens (the pre-annealing temperature is $350^{\circ} \mathrm{C}$ ).

In summary, the microstructure of the extruded specimen after T6 treatment is sensitive to the extrusion temperature, especially in the case of specimens extruded at 390 or $430^{\circ} \mathrm{C}$. However, the pre-annealing step (the suitable pre-annealing process is $350^{\circ} \mathrm{C}$ for $15 \mathrm{~h}$ ) before the T6 treatment can substantially reduce the microstructure sensitivity of the specimen to the extrusion temperature.

To further analyze the microstructure difference of the alloy after $\mathrm{T} 6$ treatment and after the pre-annealing $\left(350^{\circ} \mathrm{C}\right.$ for $15 \mathrm{~h})+\mathrm{T} 6$ treatment, we characterized the corresponding specimens by EBSD, as shown in Fig. 4. The proportion of low-angle grain boundaries was increased by the pre-annealing treatment such that the grain of the specimens extruded at different temperatures was refined to different extents. The recrystallization fraction was analyzed using the EBSD post-processing software HKL Channel5. The results show that the recrystallization fractions of the specimens extruded at 390 and $430^{\circ} \mathrm{C}$ after T6 treatment are $38.1 \%$ and $43.8 \%$, respectively, whereas those after pre-annealing + T6 treatment are dramatically lower: $13.8 \%$ and $13.0 \%$, respectively.

Table 2 shows the room-temperature mechanical properties of the specimens extruded at different temperatures after T6 treatment or after pre-annealing + T6 treatment; the representative engineering stress-engineering strain curves of the aged bars are given in Fig. 5. The tensile strengths $\left(R_{\mathrm{m}}\right)$ and yield strengths $\left(R_{\mathrm{p} 0.2}\right)$ of the specimens extruded at 390 and $430^{\circ} \mathrm{C}$ after T6 treatment are all respectively similar; however, the elongations $(A)$ are $7.0 \%$ and $9.2 \%$, respectively (i.e., the 
difference in elongation is large). In the case of the specimens extruded at 390 and $430^{\circ} \mathrm{C}$ after pre-annealing + T6 treatment, although their strengths are basically unchanged, their elongations increase substantially to $12.0 \%$ and $13.3 \%$, respectively, and the difference in elongations decreases. Meanwhile, as evident from Fig. 5, the elongations of the two kinds of spe-
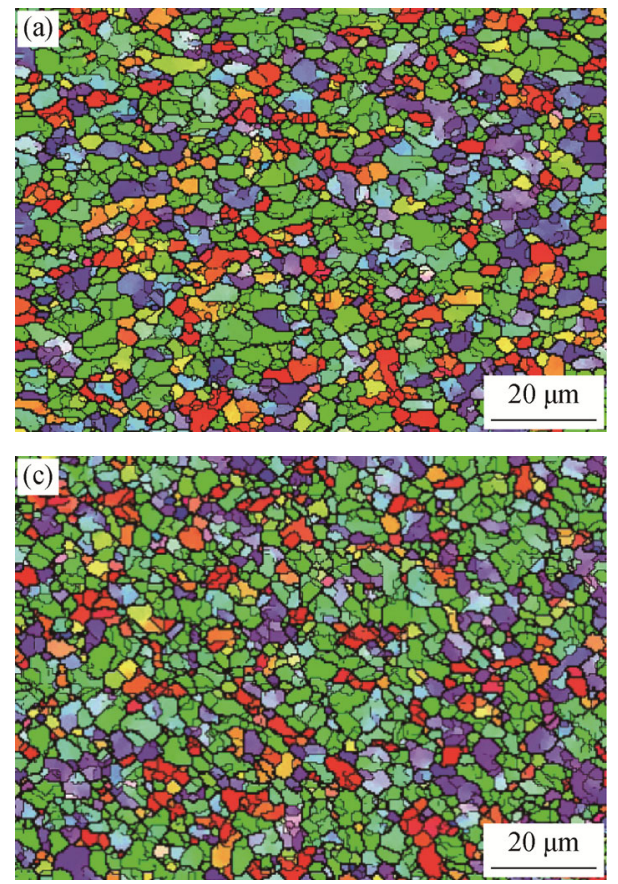

cimens after pre-annealing + T6 treatment are obviously improved and the difference between the two specimens is also smaller compared with that between the specimens after T6 treatment. Therefore, the pre-annealing treatment can, to some extent, reduce the sensitivity of the mechanical properties of the specimen to the extrusion temperature.
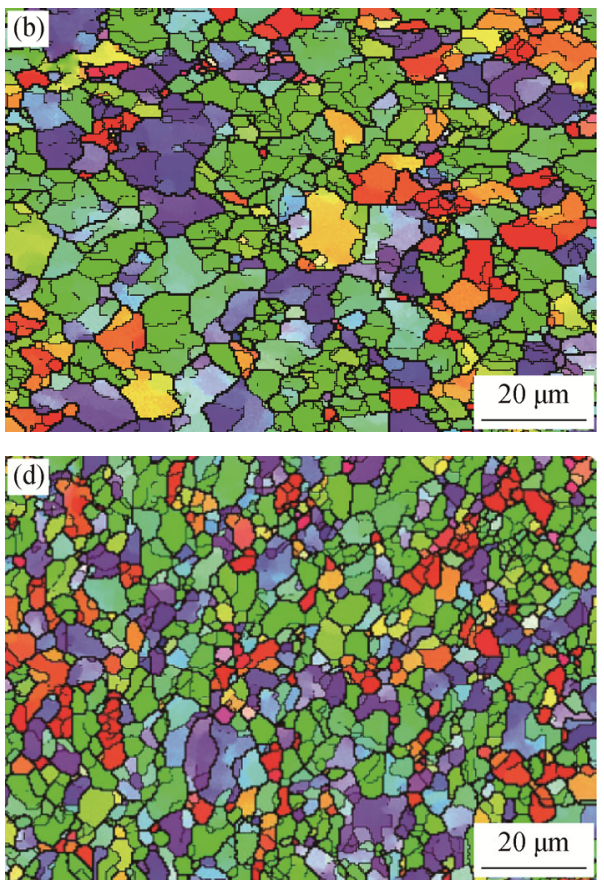

Fig. 4. EBSD images of the specimens extruded at different temperatures after different heat treatments: (a) $390^{\circ} \mathrm{C}$ extrusion $+\mathrm{T} 6$ treatment; (b) $430^{\circ} \mathrm{C}$ extrusion $+\mathrm{T} 6$ treatment; (c) $390^{\circ} \mathrm{C}$ extrusion + pre-annealing $+\mathrm{T} 6$ treatment; (d) $430^{\circ} \mathrm{C}$ extrusion + pre-annealing + T6 treatment.

Table 2. Mechanical properties of the specimens extruded at different temperatures after different heat treatments

\begin{tabular}{ccccc}
\hline Extrusion temperature $/{ }^{\circ} \mathrm{C}$ & Heat treatment & $R_{\mathrm{m}} / \mathrm{MPa}$ & $R_{\mathrm{p} 0.2} / \mathrm{MPa}$ & $A / \%$ \\
\hline 390 & $\mathrm{~T} 6$ & $666.4_{-7.7}^{+8.2}$ & $618.0_{-6.2}^{+7.8}$ & $7.0_{-0.4}^{+0.5}$ \\
430 & $\mathrm{~T} 6$ & $678.1_{-7.8}^{+5.6}$ & $618.3_{-9.4}^{+10.4}$ & $9.2_{-0.5}^{+0.6}$ \\
390 & Pre-annealing + T6 & $670.7_{-3.1}^{+4.5}$ & $625.3_{-4.3}^{+6.2}$ & $12.0_{-0.1}^{+0.3}$ \\
430 & Pre-annealing + T6 & $682.7_{-5.1}^{+6.3}$ & $623.7_{-4.6}^{+3.8}$ & $13.3_{-0.3}^{+0.2}$ \\
\hline
\end{tabular}

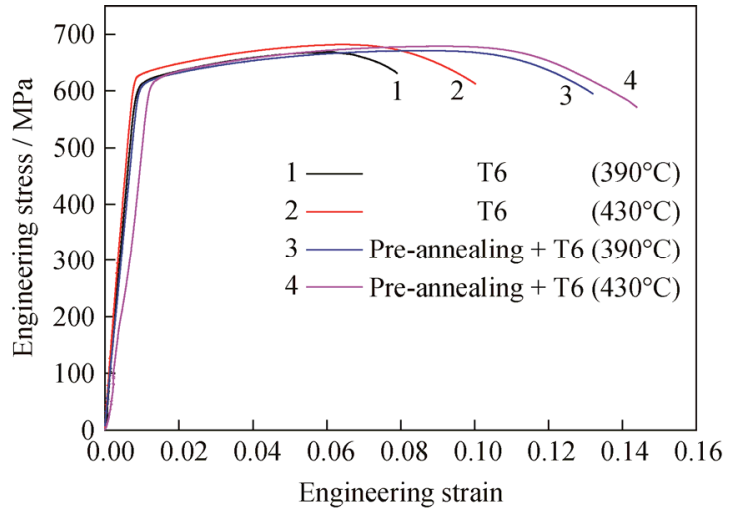

Fig. 5. Representative engineering stress-engineering strain curves of the aged bars.

\section{Discussion}

4.1. Influence mechanism of pre-annealing on the grain size of the alloy after solid-solution treatment and aging

When the 7A04 aluminum alloy billet was extruded at $390^{\circ} \mathrm{C}$, high deformation stored energy was produced, which provided a large driving force for static recrystallization during subsequent heat treatment and resulted in grain refinement. When the alloy billet was extruded at $430^{\circ} \mathrm{C}$, the deformation stored energy was diminished but was sufficient to induce static recrystallization during subsequent solution treatment. In addition, our preliminary experiment results indicated dynamic recrystallization grains with 
high-angle grain boundaries exhibited a high grain-boundary migration rate after extrusion at $430{ }^{\circ} \mathrm{C}$ of $7 \mathrm{~A} 04$ aluminum alloy. Therefore, these dynamic recrystallization grains are prone to consuming small recrystallization grains generated during the subsequent heat treatment, which induces an apparent increase in average grain size. Such behaviors result in large difference in the average grain size of the specimens extruded at 390 and $430^{\circ} \mathrm{C}$ after T6 treatment.

Pre-annealing with different annealing temperatures and times before T6 treatment influenced the microstructures of the two specimens differently. For the specimen extruded at $430^{\circ} \mathrm{C}$, when the pre-annealing temperature was less than $290^{\circ} \mathrm{C}$ or the pre-annealing time was less than $10 \mathrm{~h}$, the release of deformation stored energy was limited because of the low annealing temperature and short annealing time, which had little effect on the nucleation and growth of grains during the subsequent solution treatment. When the pre-annealing temperature was $290-380^{\circ} \mathrm{C}$ or the pre-annealing time was approximately $10-20 \mathrm{~h}$, the release of deformation stored energy increased; i.e., the driving force for static recrystallization was reduced, which influenced the nucleation and growth of recrystallization grains. Such behavior can suppress static recrystallization and retain a large number of small-angle grain boundaries, leading to different grain refinements. When the pre-annealing temperature exceeded $380^{\circ} \mathrm{C}$ or the pre-annealing time was longer than $20 \mathrm{~h}$, recrystallization occurred during pre-annealing and grains apparently grew after the solid-solution treatment, resulting in a large grain size.

For the specimen extruded at $390^{\circ} \mathrm{C}$, its deformation stored energy was higher than that of the specimen extruded at $430^{\circ} \mathrm{C}$ because of the low deformation temperature. Although the deformation stored energy was reduced after the pre-annealing treatment, subgrain formation by polygonization was substantially carried out and the subgrains continued to grow under the remaining deformation stored energy after the pre-annealing treatment. Therefore, the average grain sizes of the aged specimens extruded at $390^{\circ} \mathrm{C}$ with or without pre-annealing treatment were basically unchanged; however, only the number of small-angle grain boundaries increased.

\subsection{Influence mechanism of pre-annealing on the me- chanical properties of the alloy after solid-solution treatment and aging}

In general, the yield strength of $\mathrm{Al}-\mathrm{Zn}-\mathrm{Mg}-\mathrm{Cu}$ alloy should satisfy the Hall-Pech equation [15]:

$\sigma=\sigma_{0}+k_{\mathrm{y}} d^{-1 / 2}$

where $\sigma$ is the yield strength, $\sigma_{0}$ is the deformation resistance, $k_{\mathrm{y}}$ is the effect of grain boundaries on strength, and $d$ is the grain diameter. Parameters $\sigma_{0}$ and $k_{\mathrm{y}}$ are constant. According to Eq. (1), a smaller average grain size results in an increase in yield strength. However, the average grain size was observed to have little effect on yield strength in the present work. For example, the average grain sizes of the samples extruded at 390 and $430^{\circ} \mathrm{C}$ after T6 treatment are 3.4 and $8.1 \mu \mathrm{m}$, respectively, whereas their yield strengths are approximately the same at about $618 \mathrm{MPa}$.

Ma et al. [16] found that the main strengthening mechanism of $\mathrm{Al}-\mathrm{Zn}-\mathrm{Mg}-\mathrm{Cu}$ alloy was precipitation strengthening, which is mainly related to the size and distribution of precipitates in the aged alloy. Fig. 6 shows the TEM images of the samples extruded at different temperatures after the T6 treatment. In Fig. 6, the sizes of the matrix precipitations $(\mathrm{Mpt})$ distributed dispersively in the specimens extruded at 390 and $430^{\circ} \mathrm{C}$ are approximately the same, about $5 \mathrm{~nm}$, and the widths of the precipitate-free zone (PFZ) are also approximately the same, about $55 \mathrm{~nm}$. Precipitate particles formed at grain boundaries of the specimen extruded at $390^{\circ} \mathrm{C}$ are smaller than those formed at grain boundaries of the specimen extruded at $430^{\circ} \mathrm{C}$. Although the morphology of precipitate particles formed at grain boundaries differs, it strongly influences the corrosion resistance of the alloy and does not markedly affect the alloy's strength. Therefore, the change in average grain size has no effect on the strength of the aged specimens extruded at 390 and $430^{\circ} \mathrm{C}$, i.e., their yield strength and tensile strength are basically the same.

From Table 2, the elongations to failure of the specimens by different heat treatments differ and many factors influence the elongation. The main factors are the grain size, texture, and Mpt of the material. However, according to Fig. 6, when the specimens extruded at 390 and $430^{\circ} \mathrm{C}$ were treated by T6, the size and distribution of Mpt and the width of PFZ were approximately the same, indicating that these parameters have little effect on the plasticity of the specimens.

Macroscopic texture analysis of the specimens was carried out; the ODF of different specimens is shown in Fig. 7. The maximum intensities of the main texture components of the four specimens are shown in Table 3. A-, copper-, and S-type textures have been reported to be hard orientations [17-18], whereas cube and Gauss textures have been reported to be soft orientations. Hard orientation hinders the dislocation slip, which is detrimental to the ductility of the alloy. By contrast, the hindering effect of soft orientation toward dislocation slip is weaker than that of hard orientation; therefore, increasing the number of soft orientations is conducive to improving the plasticity of the alloy.

When the extrusion temperature was $390^{\circ} \mathrm{C}$, the average 
grain size of the specimens treated by pre-annealing $+\mathrm{T} 6$ or by $\mathrm{T} 6$ alone is approximately the same; thus, the average grain size has little effect on the plasticity of the specimens. However, a texture difference is clearly observed between the specimens subjected to different heat treatments. Although the texture components of the specimens are similar, the largest intensity of the main textures differs. The intensity of all of the textures in the specimens treated by pre-annealing $+\mathrm{T} 6$ was higher than that of the specimens treated by $\mathrm{T} 6$ alone; the soft orientation number (cube texture), in particular, increased substantially. For the sample extruded at $390^{\circ} \mathrm{C}$ following by $\mathrm{T} 6$ treatment, the substantial improvement of elongation to failure of the specimen after pre-annealing $+\mathrm{T} 6$ treatment is mainly ascribed to the increase of soft orientation.

For the specimen extruded at $430^{\circ} \mathrm{C}$, both the texture component and maximum texture intensity of the specimens treated by pre-annealing $+\mathrm{T} 6$ are similar to those of the specimens treated by T6. However, the grains of the specimen treated by pre-annealing are remarkably refined, and the average grain size decreases from 8.1 to $3.8 \mu \mathrm{m}$. Plastic deformation and crack formation of the alloy are related to the dislocation motion. According to dislocation piling-up theory [19], effective shear stress $\left(\tau_{\mathrm{e}}\right)$ which induces crack propagation can be described as

$\tau_{\mathrm{e}}=\left(\frac{2 G \gamma_{\mathrm{s}}}{d}\right)^{1 / 2}$ where $G$ is the shear modulus and $\gamma_{\mathbf{S}}$ is the interfacial surface energy. According to Eq. (2), the effective shear stress $\tau_{\mathrm{e}}$ increases with decreasing grain size $\mathrm{d}$; that is, grain refinement can improve crack propogation resistance, which enhances the plasticity of the alloy. Therefore, for the specimen extruded at $430^{\circ} \mathrm{C}$, the elongation of the specimen treated by pre-annealing $+\mathrm{T} 6$ treatment is higher than that of the specimen treated by $\mathrm{T} 6$.

In the case of the specimens extruded at 390 and $430^{\circ} \mathrm{C}$ after $\mathrm{T} 6$ treatment, their average grain sizes are 3.4 and 8.1 $\mu \mathrm{m}$, respectively. From the viewpoint of the effect of grain size on the mechanical properties, the elongation of the specimen extruded at $430^{\circ} \mathrm{C}$ should be smaller than that of the specimen extruded at $390^{\circ} \mathrm{C}$. However, the soft orientation (cube texture) in the specimen extruded at $430^{\circ} \mathrm{C}$ is much more than that in the specimen extruded at $390^{\circ} \mathrm{C}$. From the viewpoint of the effect of texture on the mechanical property, the elongation of the specimen extruded at $430^{\circ} \mathrm{C}$ is higher. A quantitative comparison of the contributions of grain size and grain orientation to plasticity of the alloy is difficult. However, on the basis of the aforementioned experimental results and analyses, in the grain size range studied in this work, the contribution of grain orientation to plasticity is larger than that of the grain size, resulting in the specimen extruded at $430^{\circ} \mathrm{C}$, which has a larger size grain and more soft orientation textures, exhibiting better plasticity.
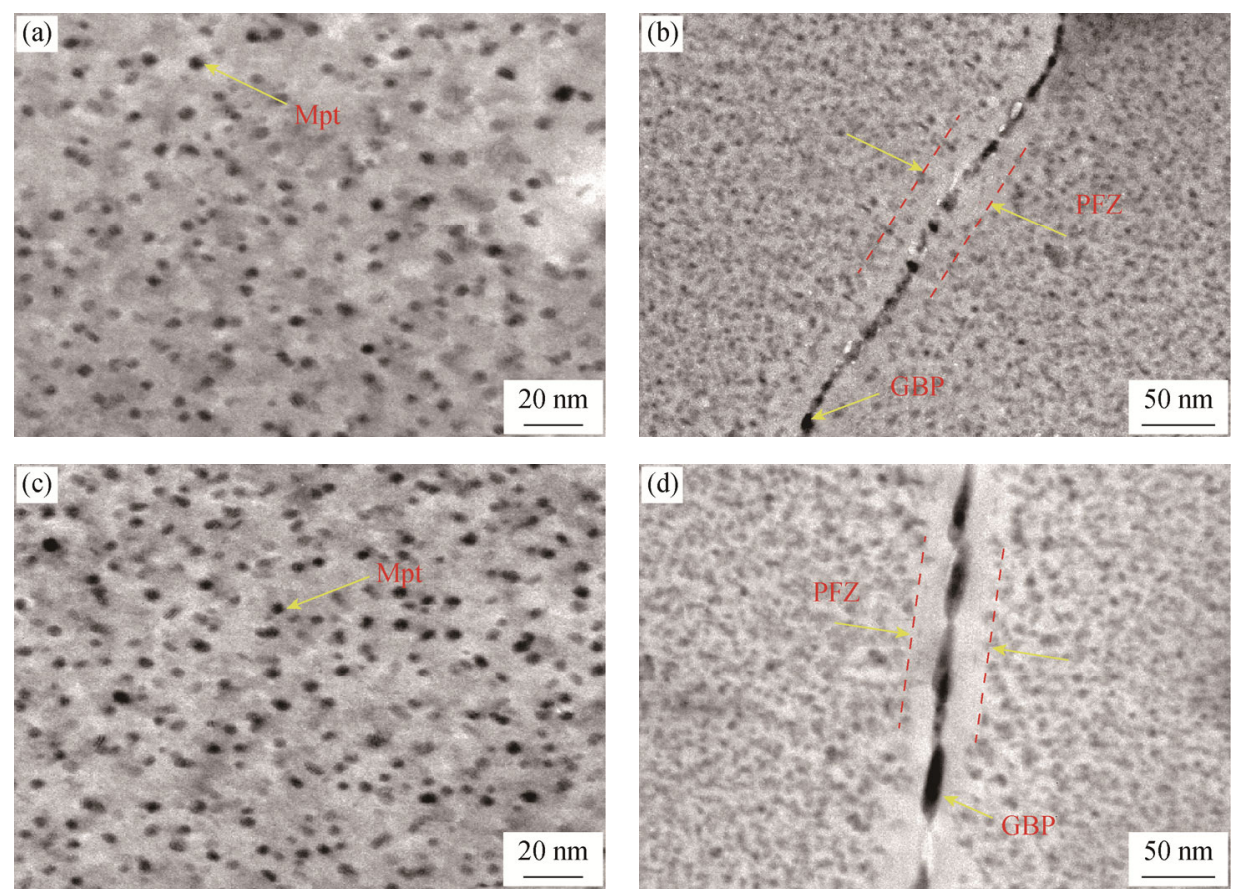

Fig. 6. TEM images of the specimens extruded at various temperatures after T6 treatment (GBP: grain boundary precipitation; Mpt: the matrix precipitation; PFZ: precipitate-free zone): (a, b) extruded at $390^{\circ} \mathrm{C}$; (c, d) extruded at $430^{\circ} \mathrm{C}$. 


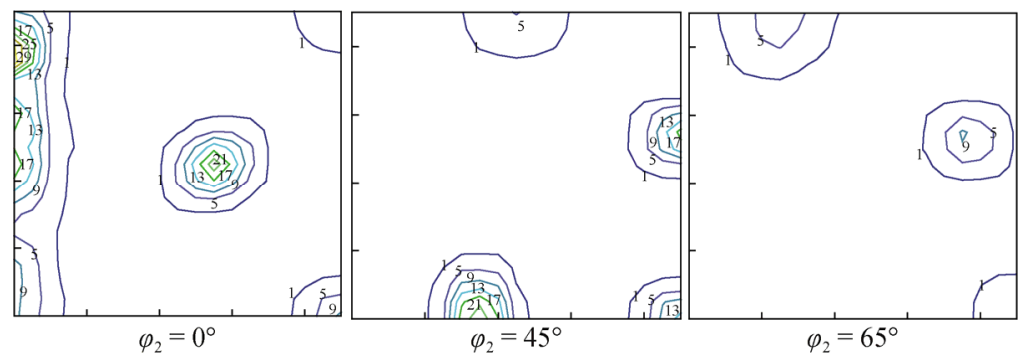

(a)

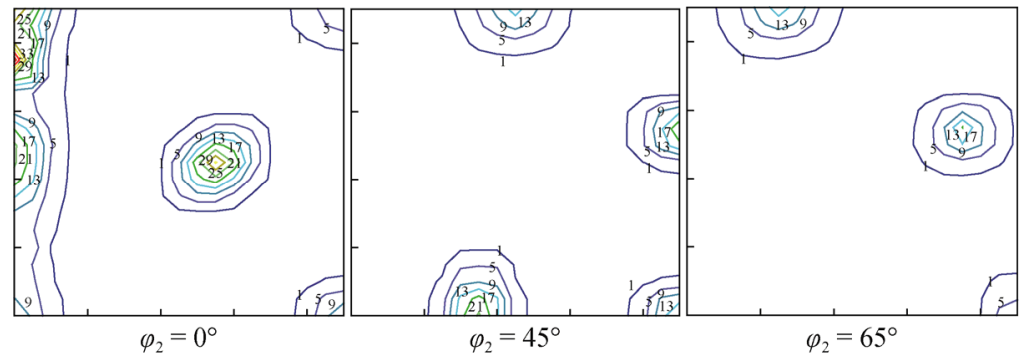

(b)

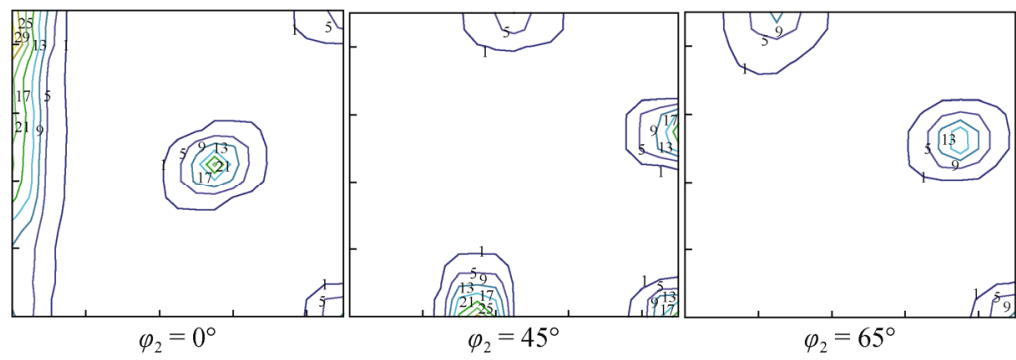

(c)

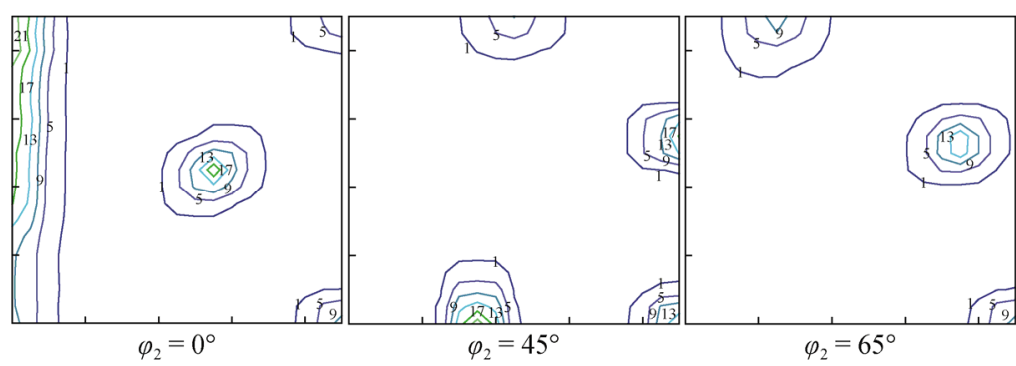

(d)

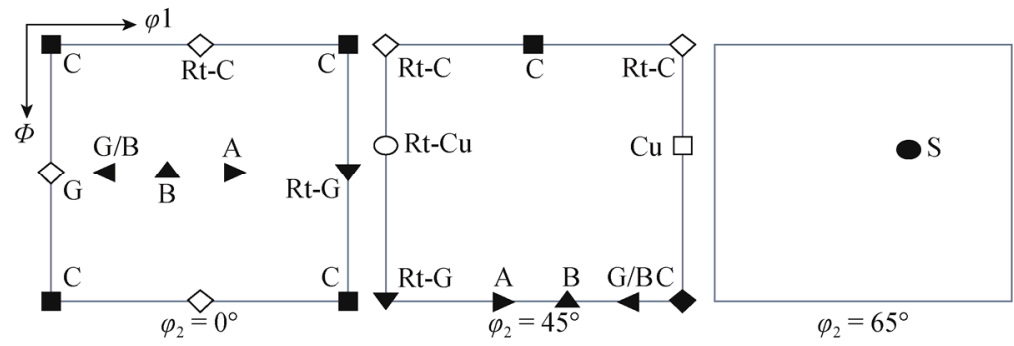

(e)

Fig. 7. Orientation distribution function (ODF) of the specimens extruded at different temperatures after different heat treatments $\left(\Phi, \varphi_{1}\right.$, and $\varphi_{2}$ : Euler angles; Rt-C: rotational cubic texture; C: cubic texture; A: A-type texture; B: brass-type texture; G: gauss texture; $\mathrm{Cu}$ : copper-type texture; $\mathrm{Rt}-\mathrm{Cu}$ : rotational copper-type texture; $\mathrm{G} / \mathrm{B}$ : transition texture of gauss texture to brass-type texture; Rt-G: rotational gauss texture; S: S-type texture; numbers in the figures: intensity of texture; curves: texture contour): (a) $390^{\circ} \mathrm{C}$ extrusion + $\mathrm{T} 6$ treatment; (b) $430^{\circ} \mathrm{C}$ extrusion + T6 treatment; (c) $390^{\circ} \mathrm{C}$ extrusion + pre-annealing + T6 treatment; (d) $430^{\circ} \mathrm{C}$ extrusion + pre-annealing + T6 treatment; (e) typical components in an ODF. 
Table 3. Maximum intensity of the main texture component of the specimens extruded at different temperatures after different heat treatments

\begin{tabular}{|c|c|c|c|c|c|c|}
\hline \multirow{2}{*}{ Extrusion temperature $/{ }^{\circ} \mathrm{C}$} & \multirow{2}{*}{ Heat treatment } & \multicolumn{5}{|c|}{ Main texture component type } \\
\hline & & A & Copper & $\mathrm{S}$ & Cube & Gauss \\
\hline 390 & $\mathrm{~T} 6$ & 22 & 17 & 10 & 9 & 18 \\
\hline 430 & T6 & 29 & 18 & 17 & 26 & 21 \\
\hline 390 & Pre-annealing + T6 & 21 & 18 & 16 & 27 & 21 \\
\hline 430 & Pre-annealing + T6 & 20 & 17 & 16 & 23 & 19 \\
\hline
\end{tabular}

The specimens extruded at 390 and $430^{\circ} \mathrm{C}$ were treated by pre-annealing $+\mathrm{T} 6$, and their elongations are basically the same because their grain sizes, texture component, and maximum intensity of the textures are basically the same.

\section{Conclusions}

(1) Pre-annealing treatment at $350^{\circ} \mathrm{C}$ for $15 \mathrm{~h}$ before $\mathrm{T} 6$ treatment can significantly reduce the sensitivity of the microstructure and mechanical properties of the extruded 7A04 aluminum alloy toward the extrusion temperature.

(2) The average grain sizes after T6 treatment of the specimens extruded at 390 and $430^{\circ} \mathrm{C}$ are 3.4 and $8.1 \mu \mathrm{m}$, respectively, and their elongations to failure are $7.0 \%$ and $9.2 \%$, respectively. However, after pre-annealing $+\mathrm{T} 6$ treatment, both the differences of their grain size and elongation of the specimens become small. Their average grain sizes are respectively 3.2 and $3.8 \mu \mathrm{m}$, and the elongations are respectively $12.0 \%$ and $13.3 \%$.

(3) For the specimens extruded at the same temperature, pre-annealing treatment before solid solution and aging can obviously improve the plasticity of the alloy, which is ascribed to an increase of soft texture (e.g., the specimen extruded at $390^{\circ} \mathrm{C}$ ) or grain refinement (e.g., the specimen extruded at $430^{\circ} \mathrm{C}$ ) in the specimens by pre-annealing $+\mathrm{T} 6$ treatment.

\section{Acknowledgement}

This work was financially supported by the National Key Technologies R \& D Program of China (No. 2016YFB0300901).

Open Access This article is distributed under the terms of the Creative Commons Attribution 4.0 International License (http://creativecommons.org/licenses/by/4.0/), which permits unrestricted use, distribution, and reproduction in any medium, provided you give appropriate credit to the original author(s) and the source, provide a link to the Creative Commons license, and indicate if changes were made.

\section{References}

[1] W.R. Hou, Z.H. Zhang, J.X. Xie, Q.M. Ma, and H.T. Gai, Temperature inhomogeneity on cross section of $\mathrm{Al}$ alloy hollow profile based on reverse point tracking method, Chin. J. Nonferrous Met., 25(2015), No. 7, p. 1798.

[2] V. Sanabria, S. Mueller, and W. Reimers, Microstructure evolution of friction boundary layer during extrusion of AA 6060, Procedia Eng., 81(2014), p. 586.

[3] W. Gu, J.Y. Li, and Y.D. Wang, Effect of grain size and taylor factor on the transverse mechanical properties of 7050 aluminium alloy extrusion profile after over-aging, Acta Metall. Sin., 52(2016), No. 1, p. 51.

[4] T. Kayser, B. Klusemann, H.G. Lambers, H.J. Maier, and B. Svendsen, Characterization of grain microstructure development in the aluminum alloy EN AW-6060 during extrusion, Mater. Sci. Eng. A, 527(2010), No. 24-25, p. 6568.

[5] J. Chen, Z. Liang, S. Dai, W. Shao, and B. Zhang, Effects of grain shape and texture on the through-thickness yield strength of AA7055 aluminum alloy plate, Rare Met. Mater. Eng., 37(2008), No. 11, p. 1966.

[6] J.Y. Li, J.X. Xie, Y. Song, S. Yin, and W. Gu, The Isothermal Extrusion System and Method for Aluminum Magnesium Alloy Based on the Fuzzy Closed-Loop Control of Temperature, Chinese Patent, Appl. ZL201110346836.3, 2013.

[7] J.X. Xie, J.Y. Li, Y.L. Chen, and B. Liu, Device and Control System for Realizing Temperature Gradient Distribution of Extrusion Billet, Chinese Patent, Appl. ZL200910237523.7, 2011.

[8] C. Tan, X.J. Xu, W. Jiang, L.S. Sun, L.X. Zhang, Y.Z. Fan, and J.J. Zhao, Effect of pre-recovery treatment on microstructure and properties of ultra high strength aluminum alloy extrusion treated by solid solution-T652 treatment, Chin. J. Nonferrous Met., 25(2015), No. 11, p. 3019.

[9] X.J. Xu, Y.K. Zhang, P.A. Deng, Y. Wu, Z.Q. Zhang, and Y.D. $\mathrm{Lu}$, Effect of pre-recovery-annealing treatment on micro- 
structure and properties of extruded 7085 aluminum alloy, Trans. Mater. Heat Treat., 35(2014), No. 8, p. 36.

[10] X.M. Zhang, Z.B. Huang, S.D. Liu, W.H. Liu, C. Zhang, and Y. Du, Effects of two-stage solution on microstructures and mechanical properties of 7A55 aluminum alloy, Chin. J. Nonferrous Met., 16(2006), No. 9, p. 1527.

[11] K.H. Chen, H. Chao, H.C. Fang, D.H. Xiao, and S.Y. Chen, Effect of step-solution on microstructure and local corrosion properties of $\mathrm{Al}-\mathrm{Zn}-\mathrm{Mg}-\mathrm{Cu}$ aluminum alloy, J. Cent. South Univ. Sci. Technol., 41(2010), No. 5, p. 1730.

[12] X.F. Xu, Y.G. Zhao, X.D. Wang, Y.Y. Zhang, and Y.H. Ning, Effect of rapid solid-solution induced by electropulsing on the microstructure and mechanical properties in $7075 \mathrm{Al}$ alloy, Mater. Sci. Eng. A, 654(2016), No. 27, p. 278.

[13] H.J. Bunge, Texture Analysis in Materials Science, Butterworths Press, London, 1982, p. 88.

[14] K. Lücke, J. Pospiech, K.H. Virnich, and J. Jura, On the problem of the reproduction of the true orientation distribu tion from pole figures, Acta Metall., 29(1981), No. 1, p. 167.

[15] G.X. Hu, X. Cai, and Y.H. Rong, Fundamentals of Materials Science, Shanghai Jiao Tong University Press, Shanghai, 2010, p. 97.

[16] K.K. Ma, H.M. Wen, T. Hu, T.D. Topping, D. Isheim, D.N. Seidman, E.J. Lavernia, and J.M. Schoenung, Mechanical behavior and strengthening mechanisms in ultrafine grain precipitation-strengthened aluminum alloy, Acta Mater, 62(2014), No. 5, p. 41.

[17] M.J. Starink and S.C. Wang, A model for the yield strength of overaged Al-Zn-Mg-Cu alloys, Acta Mater, 51(2003), No. 17, p. 5131.

[18] F.J. Hmmphrey and M. Hatherly, Recrystallization and Related Annealing Phenomena, 2nd Ed., Pergamon Press, London, 2004, p. 86.

[19] G. Terlinde and G. Luetjering, Influence of grain size and age-hardening on dislocation pile-ups and tensile fracture for a Ti-Al alloy, Metall. Trans. A, 13(1982), No. 7, p. 1283. 